\title{
ANÁLISE SOCIOAMBIENTAL DO ARROIO SANTO ANTÔNIO - PASSO FUNDO - RS
}

\author{
SOCIAL AND ENVIRONMENTAL ANALYSIS STREAM OF ST. \\ $A N T H O N Y$ - PASSO FUNDO - RS
SOCIO ANÁLISIS DEL MEDIO AMBIENTE DEL ARROYO SAN ANTONIO - PASSO FUNDO - RS

\author{
Alcindo Neckel \\ Professor do Curso Superior de Tecnologia em Gestão Ambiental da FAC PORTAL. \\ Graduado em Geografia e Mestre em Engenharia com concentração em Infra-estrutura e meio \\ ambiente pela Universidade de Passo Fundo-RS. \\ Rodovia RS 153, 555, Passo Fundo - RS - CEP. 99034-600 \\ E-mail: alcindoneckel@yahoo.com.br
}

\author{
Alexsandro Luiz Julio \\ Prof. Msc. Universidade do Contestado - UnC \\ Rua Victor Sopelsa, 3000, bairro Salete, Concórdia - SC - CEP. 89700-000 \\ E-mail:alj@uncnet.br
}

\section{Emanuelle Goellner}

Professora da FAC PORTAL. Mestranda em Engenharia Civil, área de concentração infraestrutura e meio ambiente - Universidade de Passo Fundo-RS.

Rodovia RS 153, 555, Passo Fundo - RS - CEP. 99034-600

E-mail: goellner@yahoo.com.br

\section{Luciana Brandli}

Professora Adjunta II da Universidade de Passo Fundo-RS.

Doutora em Engenharia de Produção pela Universidade Federal de Santa Catarina.

Rodovia RS 285 km 171, bairro São José, Passo Fundo - RS - CEP. 99052-900

brandli@upf.br

\section{Resumo}

O crescimento da população urbana mundial tem sido responsável por grandes alterações ambientais, especialmente em recursos hídricos. Este artigo apresenta um diagnóstico socioambiental do arroio Santo Antônio, afluente do rio Passo Fundo, localizado em Passo Fundo, cidade de médio porte, ao sul do Brasil. Identificou-se os níveis de degradação ambiental e a sua interferência na qualidade de vida da população ribeirinha, além de um levantamento socioeconômico da população. Os resultados apresentam um diagnóstico sobre a atual situação do 
arroio, características da população ribeirinha e problemas infraestruturais mais urgentes. A pesquisa revela um processo de violenta degradação, manifestada através das alterações vegetais, do lançamento de esgotos domésticos e de resíduos sólidos. Este trabalho tem a intenção de servir de aporte teórico a futuros trabalhos científico, visando um estudo da qualidade hídrica e as relações dos habitantes ribeirinhos com o arroio.

Palavras-chave: urbanização, arroio, meio ambiente, infraestrutura.

\begin{abstract}
The growth of world-wide urban population has been responsible for great environmental changes, especially in water resources. This article presents a diagnostic socioenvironmental of the stream Santo Antonio, Passo Fundo river's affluent, located in a city at the south of Brazil. Our study identified the levels of environmental degradation and its interference in the marginal population's quality of life, beyond a socioeconomic survey of the population. The results present the stream's diagnosis on the current situation, the characteristics of the marginal population and infrastructural problems. The research shows that a violent degradation process is manifested through the land cover alterations and the domestic sewers and solid waste deliberation in the stream of this region. This work had also the aim to advice, with theoretical support, other scientific works, focusing at the water quality study and the relations between marginal inhabitants and the stream.
\end{abstract}

Key-words: urbanization, stream, environment, infrastructure.

\title{
Resumen
}

El crecimiento de la población urbana ha sido responsable de importantes cambios ambientales, especialmente en los recursos hídricos. En este artículo se presenta un diagnóstico socio-ambiental del arroyo de Santo Antônio, un afluente del río Passo Fundo, ubicado en Passo Fundo, una ciudad de tamaño medio en el sur de Brasil. Identificados los niveles de degradación ambiental y su interferencia en la calidad de vida del río, y una encuesta socioeconómica de la población. Los resultados presentan un diagnóstico sobre la situación actual de la corriente, las características de una infraestructura fluvial y problemas más urgentes. La investigación revela un violento proceso de degradación, que se manifiesta a través de cambios verduras, la liberación de aguas residuales domésticas y residuos sólidos. Este trabajo está destinado a servir de base teórica para el trabajo científico futuro con el fin de estudiar la calidad del agua y las relaciones con los habitantes ribereños del río.

Palavras-llaves: urbanización, arroyo, medio ambiente, infraestructura.

\section{Introdução}

O crescimento da população urbana mundial tem sido responsável pelas grandes alterações ambientais. As mudanças mais notáveis no meio físico referemse às alterações hidrológicas, geomorfológicas, climáticas, de cobertura vegetal e na qualidade da água e do ar. Neste contexto, tais mudanças podem ser 
identificadas como geoindicadores, mesmo que eles não tenham sido desenvolvidos para o ambiente urbano. Essas alterações requerem monitoramento urgente e detalhado (TAVARES et al., 2007).

Nesse desequilíbrio ambiental encontra-se em evidência a poluição das águas, bastante agravada nos dias de hoje, maior em zonas urbanas onde grandes quantidades de resíduos sólidos são indiscriminadamente depositados nos recursos hídricos. Outro agravante é a poluição industrial, que muitas vezes lança seus efluentes sem tratamento, resultando na contaminação das águas (ELDHO, 2007).

A formação das cidades brasileiras, desde 1950, vem construindo um cenário de contrastes, típico das cidades de países em desenvolvimento. Conforme Nefussi e Licco (2005, p.1), "o resultado tem sido o surgimento de cidades sem infraestrutura e disponibilidade de serviços urbanos capazes de comportar o crescimento provocado pelo contingente populacional que migrou para elas".

Observa-se grandes transformações no espaço geográfico, através de intensos estágios exploratórios, numa dinâmica que surge com as primeiras ocupações, até o aprimoramento das grandes áreas urbanas, hoje presentes em todo o mundo (DAMAS, 2005). Para Duarte e Brito (2006), ao longo do tempo, o homem vem utilizando o solo de maneira degenerativa ou preservativa. O manejo incorreto do solo provocou, e vem provocando, a degradação do meio ambiente. Esse processo deve-se, principalmente, pela ocupação humana acompanhada da falta de planejamento.

Com a expansão das cidades brasileiras, agravaram-se os níveis de degradação ambiental, estando estes fortemente ligados a fatores de ocupação e uso do solo, uma vez que as formas de ocupação e manejo ocasionam o tipo e o grau de impacto, que atinge de maneiras diferentes o espaço geográfico (FANTON, 2007).

A visão de Souza (2004, p.73) sobre o ideal de crescimento sustentável para o século XXI indica que as pessoas deverão ir morar em áreas de habitação separadas por grandes parques verdes, interligadas por transportes coletivos de alta tecnologia, novas tecnologias limpas serão utilizadas e, mais importante ainda, políticas de equidade social e ecológica serão cada vez mais pesquisadas. Consequentemente, as cidades poderão passar de zonas focais de grandes distúrbios, para locais de crescimento cultural e de compartilhamento de idéias, tanto ecológicas quanto tecnológicas. Essa parece ser a única forma da 
sobrevivência futura. Nesse sentido, a gestão é a superação de problemas, especialmente de fatores de injustiça social, e da melhoria da qualidade de vida. Ainda afirma Souza (2004), em se tratando de "planejamento e gestão urbanos, vistos por essa ótica de ciência social, nada mais são que estratégias de desenvolvimento urbano, alimentadas por pesquisa social básica, tanto teórica quanto empírica (ou seja, diagnósticos)".

No entanto, através de teorias empíricas, existem autores clássicos como Chaffun (1997) que enfatizam os processos naturais. Porém, se esses processos fossem reconhecidos e aproveitados, representariam um poderoso recurso para a construção de um habitat urbano sustentável; mas, ignorados, ampliam os problemas que cada vez mais castigam as cidades.

Esses problemas ambientais, decorrentes da ação humana aumentaram conforme o crescimento das cidades e dos aglomerados urbanos. Essas agressões ao meio ambiente ocorrem devido a um somatório de fatores, ligados basicamente ao uso e ocupação desordenados do solo, ao crescimento da malha urbana sem o acompanhamento adequado de recursos de infraestrutura e a expansão imobiliária.

Assim, áreas inadequadas são ocupadas pela população carente, ou mesmo por empreendimentos imobiliários, acarretando no comprometimento dos recursos ambientais (LORENSINI et al., 2008). Isto é reafirmado por Marques Neto e Viadana (2006, p.18), que apontam que em áreas de grande adensamento urbano, onde a paisagem natural foi substituída em sua quase totalidade por uma paisagem construída e antropizada, as matas ciliares são, quase sempre, o único habitat favorável para uma série de espécies que compõem a fauna local. Nesse contexto, a importância desses ecossistemas deve ser colocada em destaque.

Nessa afirmação, o mesmo autor expõe a ideia de que a cidade pode ser entendida como um ecossistema, em seu sentido amplo, uma unidade ambiental, dentro das quais todos os elementos e processos do ambiente são interrelacionados e interdependentes, de modo que uma mudança em um deles resultará em alterações. Porém, há também diferenças ideológicas e conflitos de interesses que se confrontam no ideário ambiental, refletido dentro do cenário urbano (LEFF, 2003). 
Atualmente, no cenário urbanístico, a água torna-se uma preocupação, pois, mesmo sendo um recurso natural renovável, em se tratando de água potável, o consumo é cada vez maior, e o saneamento básico nem sempre chega a todas as residências. Sabe-se que o esgoto é direcionado para arroios e/ou córregos, tornando-os altamente poluídos. Assim, como comenta Magossi e Bonacella (2003, p. 34): "a contaminação das águas pelo esgoto urbano resulta em dois problemas muito sérios: a contaminação por bactérias causadoras de doenças e a contaminação por substâncias orgânicas capazes de serem transformadas por microorganismos".

Uma das evidências preocupantes, dentro da cidade, é a questão dos problemas sobre a degradação dos recursos hídricos, localizados geralmente nas zonas envolventes das áreas edificadas, nos trechos urbanos, que recebem descargas de águas residuais domésticas e industriais: adiciona-se, ainda a destruição da mata ciliar e a canalização, trazendo consequências diretas ao ecossistema ribeirinho (TEIGA et al., 2007).

Nesse sentido, o quadro de desequilíbrio dos recursos hídricos urbanos, com os problemas ambientais associados às enchentes e à deterioração da qualidade das águas, resultam não só da descarga de efluentes, mas também da ocupação inadequada do solo das bacias urbanas (BRAGA; CARVALHO, 2003). As matas ciliares são ecossistemas estruturalmente complexos, segundo Marques Neto e Viadana (2006, p.11), tendo "a responsabilidade de associar um grande número de espécies que buscam as condições favoráveis desses ambientes para a reprodução, pela disponibilidade de alimento, água, entre outros fatores”.

Com relação às condições ambientais e à contaminação da água do arroio Santo Antônio, na cidade de Passo Fundo, RS, a população fica à mercê das contaminações locais e das absorvidas pelas águas ao longo de seu trajeto. $\mathrm{Na}$ busca de informações detalhadas sobre o local de estudo, buscou-se informações sobre os níveis de degradação ambiental e a sua interferência na qualidade de vida da população ribeirinha, além de um levantamento socioeconômico para avaliar a qualidade de vida da população.

\section{Método de pesquisa}




\section{Delimitação da área de estudo}

A pesquisada foi realizada no município de Passo Fundo, situado no norte do Estado do Rio Grande do Sul. A cidade de Passo Fundo é rica em recursos hídricos, porém, mal conservados. Dentre eles está o arroio Santo Antônio, afluente da margem esquerda do rio Passo Fundo, nascendo próximo à área industrial, na Vila Mattos, à leste da cidade, entre a estrada de ferro e a rodovia RS-324, saída para o município de Marau. A área em estudo é atualmente ocupada por habitações irregulares, provocando grandes problemas ambientais.

$\mathrm{O}$ arroio Santo Antônio nasce no perímetro rural, possuindo um trecho de $2 \mathrm{~km}$ na área urbana, conforme pode ser observado na figura 1.

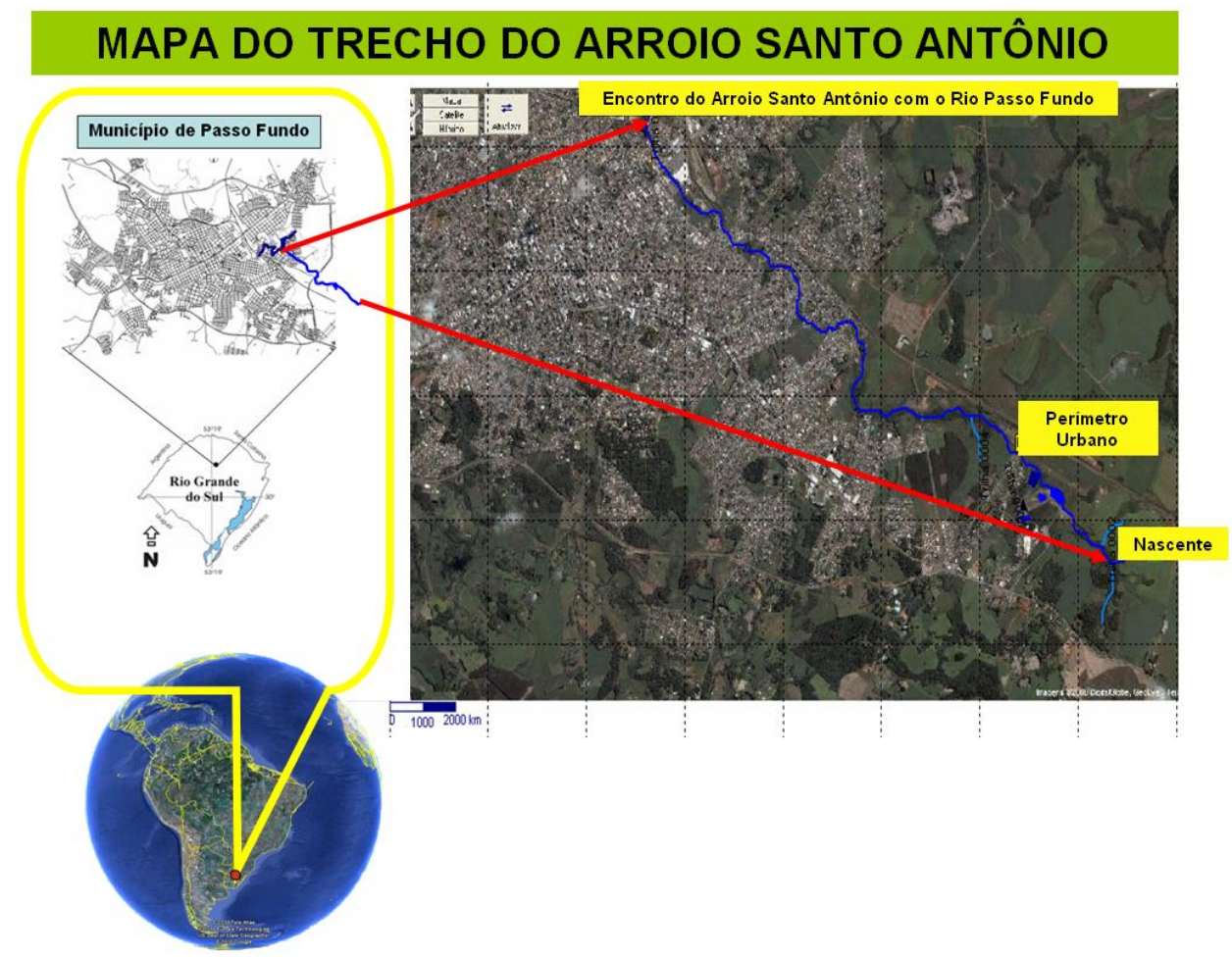

Figura 1 - Localização da área de estudo em ralação ao território nacional, com linhas imaginárias sobre o terreno. Fonte: Imagem de Google Maps obtida em setembro de 2008, georreferenciamento por GPS no software TrackMaker.

\section{Etapas da pesquisa}


De acordo com Teiga et al. (2007), a única maneira de conhecer um rio é através do monitoramento do mesmo. Isso permite determinar a situação de alguns indicadores de qualidade, assim como notificar e denunciar os problemas que se detectam.

As etapas da pesquisa compreenderam:

I) mapeamento do arroio: coletou-se informações por GPS, as quais permitiram um mapeamento detalhado de todo o canal;

II) levantamento de informações, através da aplicação de cento e seis questionários, abrangendo $100 \%$ da população existente nas margens do arroio Santo Antônio. Foram coletadas informações a cerca das características socioeconômicas da população ribeirinha e sua percepção quanto ao meio ambiente;

III) levantamento ambiental com visitas ao local de estudo e verificação da situação quanto à vegetação já existente, e análise microbiológica da água no trecho do perímetro urbano e na nascente do arroio;

IV) levantamentos bibliográficos das leis e de autores que elucidam as tendências de uso de áreas urbanas, tomando por referência a questão da degradação ambiental.

Coletou-se informações para obtenção de futuras propostas para o melhoramento da área, visando proporcionar uma melhor qualidade de vida a população ribeirinha. $\mathrm{Na}$ área em estudo, acompanhou-se as ações da comunidade, num período de dois anos (2007 e 2008).

\section{A atual situação do A rroio Santo Antônio}

A nascente formadora do arroio Santo Antônio encontra-se preservada, conforme as leis ambientais. Os 50m de área de preservação permanente (APP), conforme a resolução do Conselho Nacional do Meio Ambiente - CONAMA 303/2002 (CONAMA, 2002), estão identificados e visualizados através da figura 2. 


\section{CATELIÊ GEOGRÁFICO ISSN: 1982-1956 REVISTA ELETROONICA UFG - IESA}

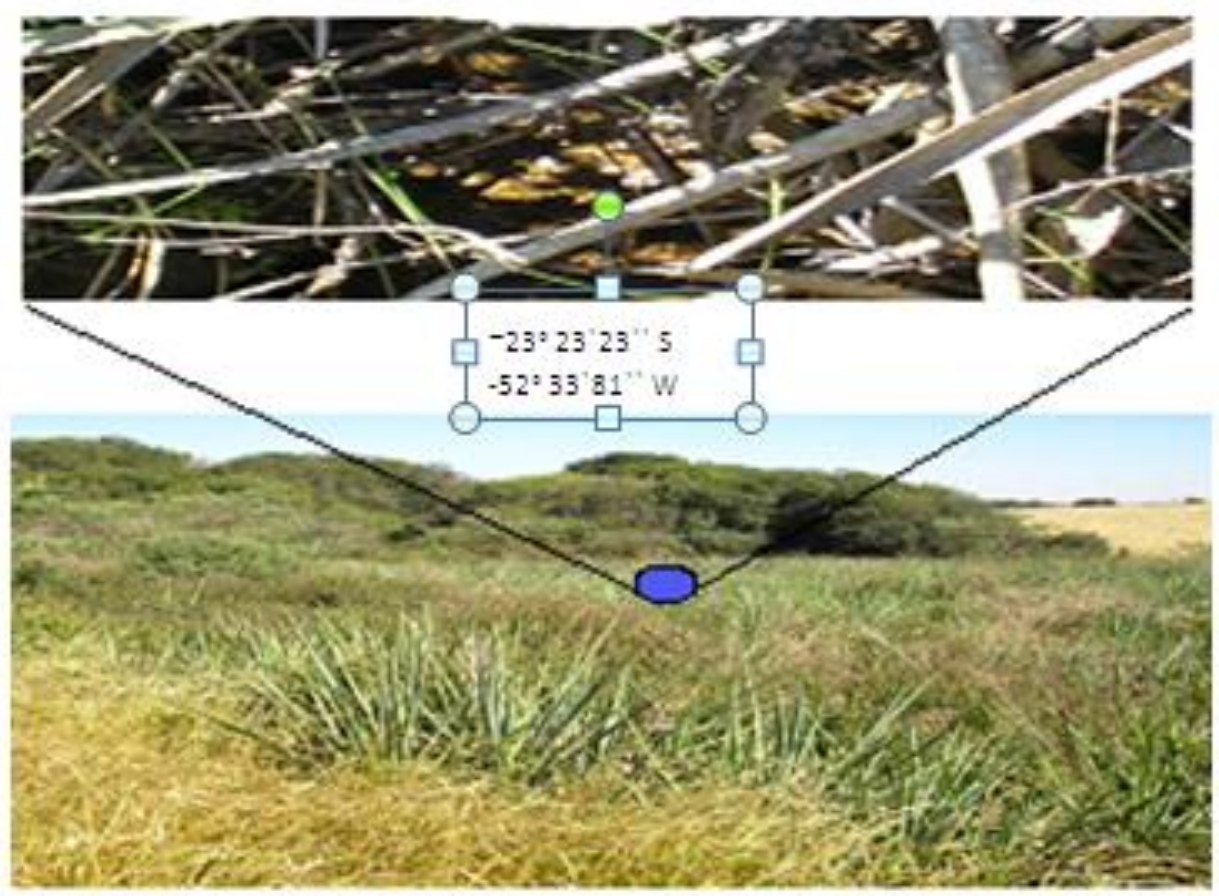

Figura 2 - Aspectos da nascente do arroio Santo Antônio, com as coordenadas exatas da nascente do mesmo - Set/2008

A mata ciliar nesse contexto encontra-se em bom estado de preservação ambiental. Visualiza-se na figura 3 o cumprimento às leis ambientais. São exigidos para cursos de água com até 10 metros de largura uma distância de 30 metros de mata ciliar, conforme a resolução 303/2002 do CONAMA.

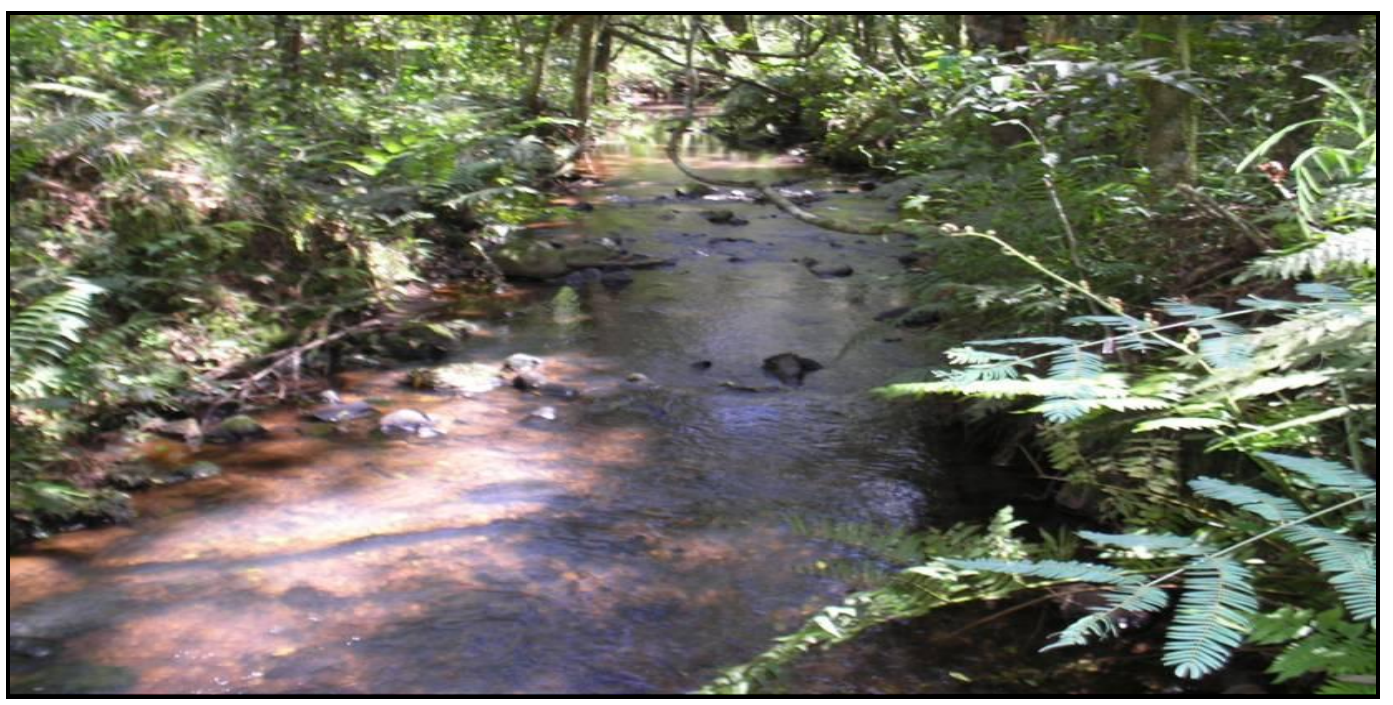

Figura 3 - Visualização da existência de mata ciliar, às margens do arroio Santo Antônio. 


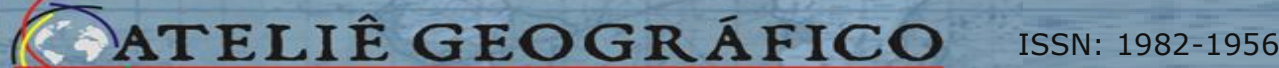 REVISTA ELETRONNICA

Após, aproximadamente, 500 metros à jusante da nascente, começa a degradação ambiental do arroio, devido ao acelerado crescimento urbano e à instalação de indústrias próximas às margens do mesmo. Nesse sentido, a própria vazão do arroio é comprometida, como revela a figura 4, com uma tubulação de captação de água para atendimento industrial. Isso ocasiona um problema ambiental, pois algumas indústrias captam água e negligenciam no tratamento de seus efluentes industriais, despejando poluentes para o leito do arroio, sejam eles orgânicos ou inorgânicos. Conforme Magossi e Bonacella (2003), em estudos realizados no Brasil, concluiu-se que o desenvolvimento industrial ocorrido nas últimas décadas tem sido um dos principais responsáveis pelo comprometimento das águas.

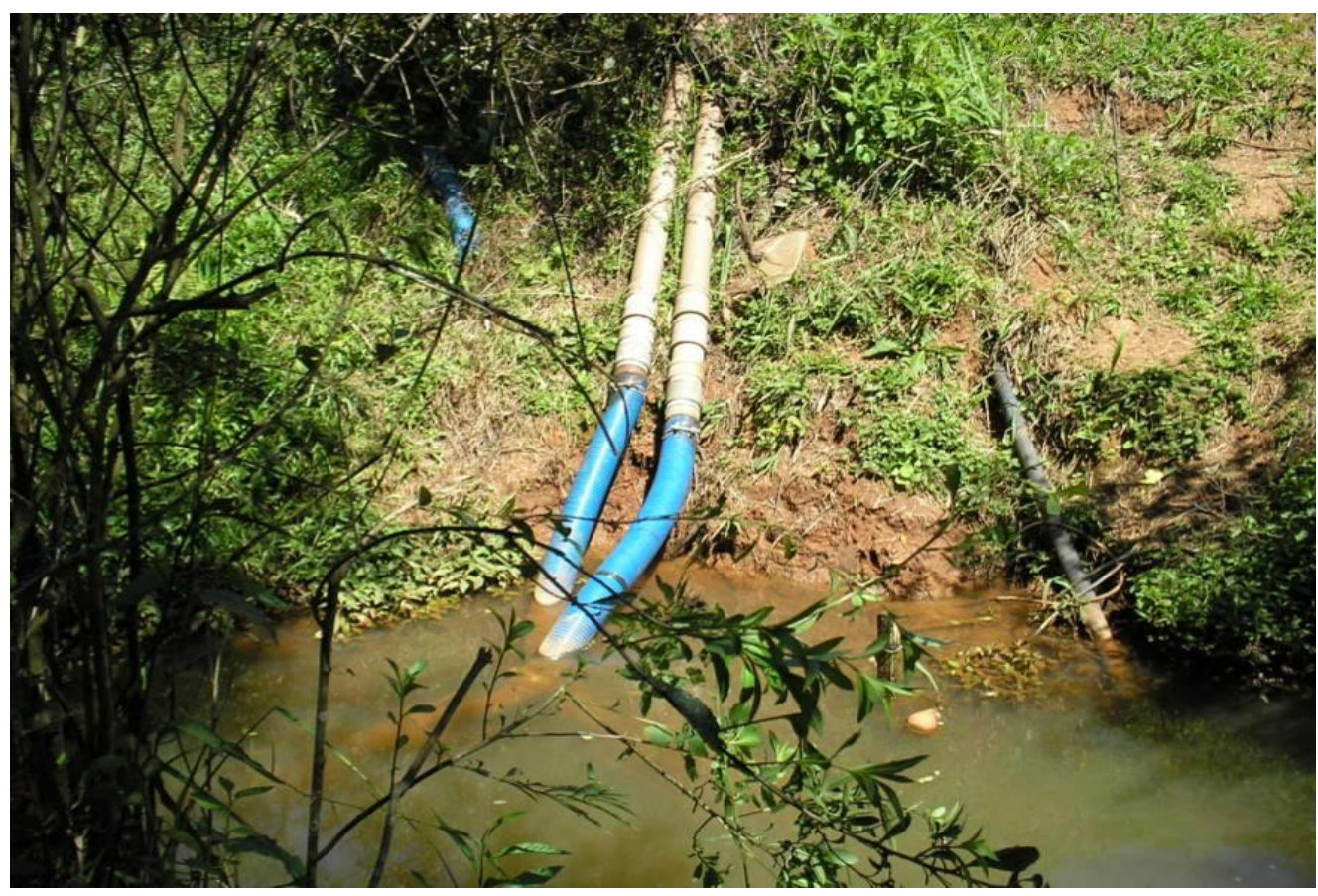

Figura 4 - Aspectos que comprovam a captação de água no arroio Santo Antônio, bem como a inexistência de mata ciliar, provocando erosão.

A grande maioria dos esgotos domiciliares, gerados pela população ribeirinha, é diretamente canalizado ao curso d'água do arroio Santo Antônio, conforme a figura 5. Esses efluentes são lançados nesse recurso hídrico sem nenhum tratamento prévio. Constatou-se existir grandes riscos de contaminações, causando doenças à população, pois, “a contaminação das águas pelos esgotos 
urbanos resulta em dois problemas muitos sérios: a contaminação por bactérias causadoras de doenças e a contaminação por substâncias orgânicas" (MAGOSSI; BONACELLA, 2003, p. 34).

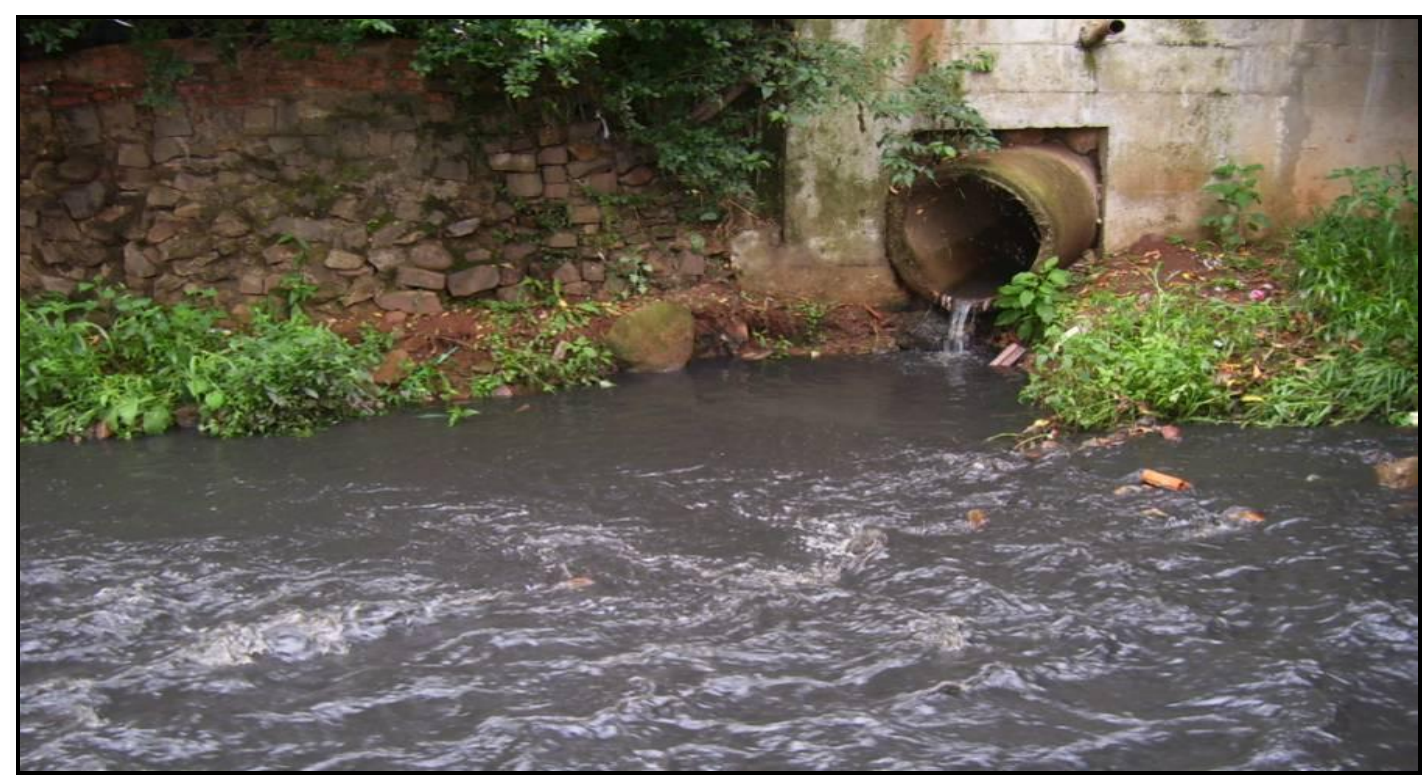

Figura 5 - Tubulação pela qual é lançado no arroio o esgoto in natura (sem qualquer tratamento).

Os moradores suprimiram a vegetação e construíram suas moradias nesses locais, desrespeitando as leis ambientais, como a resolução CONAMA 303/2002. Quase toda a mata ciliar foi removida dando lugar a moradias irregulares. Isso mostra também a falta de planejamento urbano, pois "inundações são um dos processos que mais recebem influência da urbanização" (OLIVEIRA, 1990, p. 35).

$\mathrm{O}$ arroio Santo Antônio em alguns trechos dentro do perímetro urbano encontra-se parcialmente canalizado. Consequentemente, essas canalizações quando feitas de modo irregular, podem trazer vários problemas urbanos, pois conforme Oliveira (1990), "o aumento da probabilidade de inundação a montante de um recurso hídrico, contribue para os processos erosivos das margens, pondo em risco a infraestrutura urbana e a população que reside próximo a estes lugares". A figura 6 apresenta um exemplo do problema citado. 

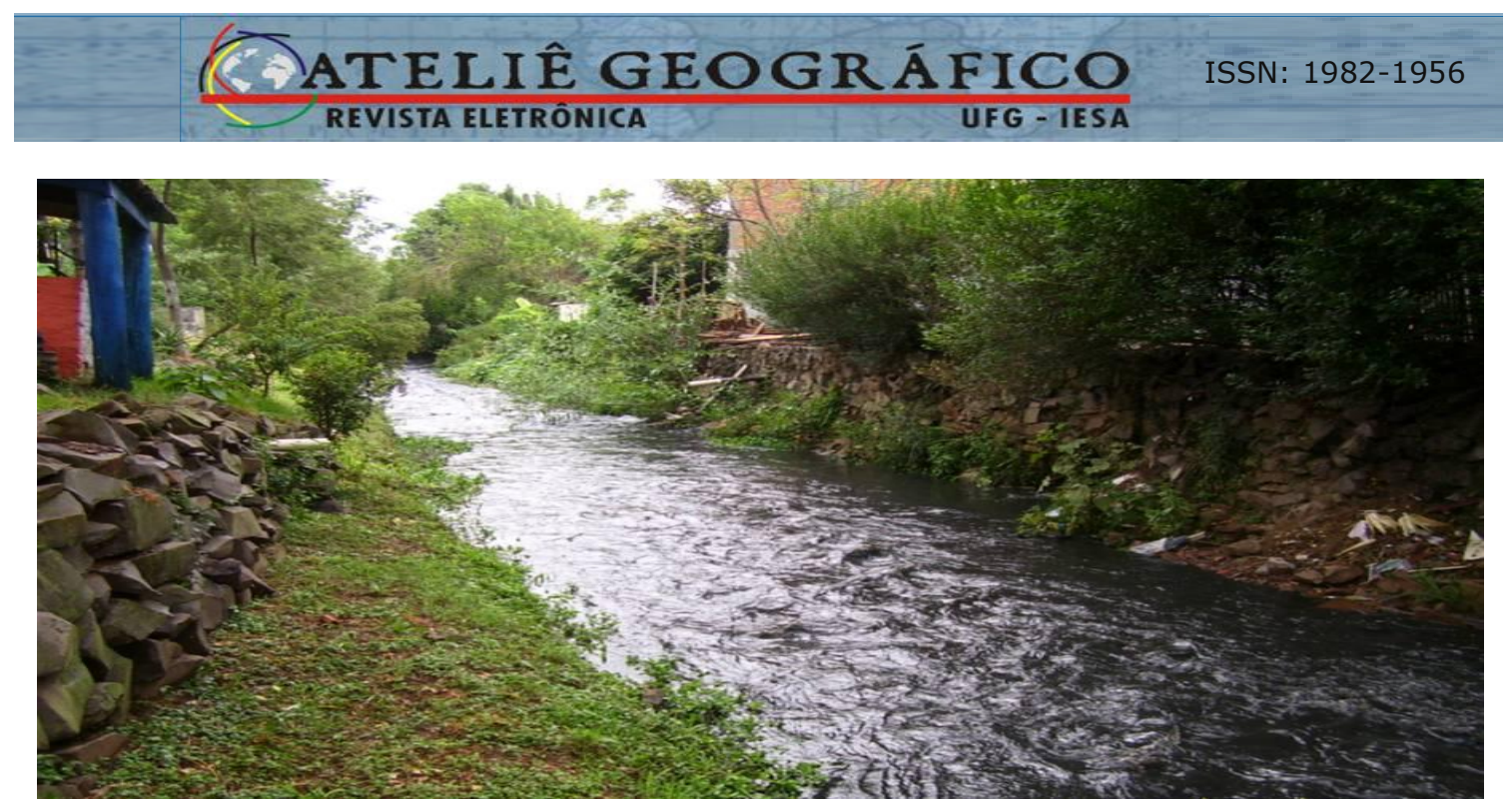

Figura 6 - Casas em área de risco, mostrando a inexistência de planejamento urbano.

Para um planejamento urbano adequado foi elaborado pela municipalidade de Passo Fundo, em 2004, o novo Plano Diretor de Desenvolvimento Integrado (PDDI). O mesmo apresenta soluções e prioridades para o município de Passo Fundo e com destaque aos recursos hídricos. Isso pode ser visualizado no Art. 19 do Plano Diretor, que estabelece normas específicas para ocupação do solo, visando-se a proteção dos recursos naturais em áreas de mananciais, priorizando assim ações que minimizem os processos de degradação ambiental.

Quando essas leis municipais forem implantadas no arroio Santo Antônio, melhorias serão observadas diretamente no meio biótico e antrópico, pois, conforme Neckel (2007, p. 22) “o Plano Diretor de Desenvolvimento Integrado (PDDI), vem auxiliar na preservação ambiental do município de Passo Fundo". No entanto, enquanto o plano diretor não é aplicado, as pessoas continuam vivendo em áreas de risco.

Neste sentido, tornam-se fundamentais as ações de educação ambiental, pois os moradores ribeirinhos do arroio Santo Antônio têm que compreender melhor as questões ambientais para realizarem ações corretas de preservação. A grande escassez de água potável prevista para o século XXI exige urgência na mudança de atitudes dos ribeirinhos. 


\section{Resultados e discussões}

Primeiramente foi realizada pesquisa para conhecer o perfil da população que vive às margens do arroio Santo Antônio, levantando-se número de habitantes por residência, com objetivo de identificar a abrangência das necessidades familiares. Os números estão expressos no gráfico da figura 7.

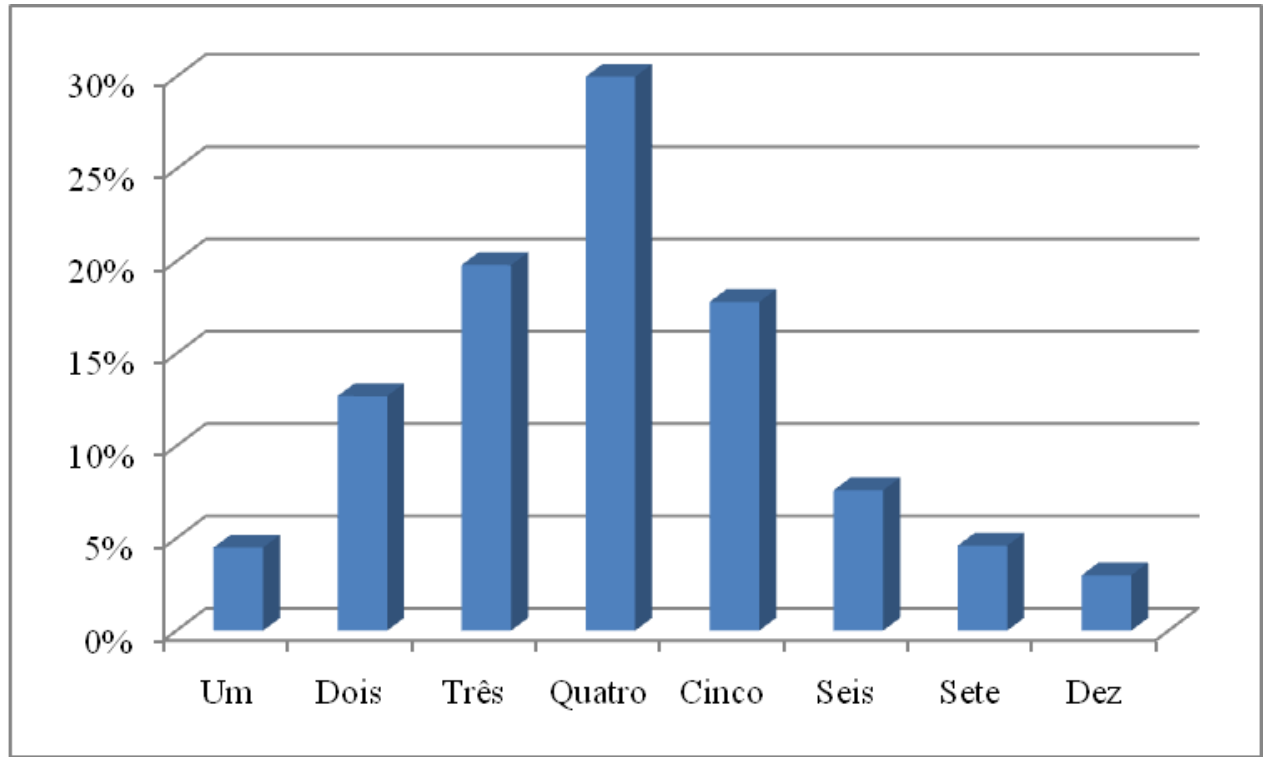

Figura 7 - Número de habitantes por residência.

Em sua maioria, as famílias são compostas por quatro pessoas, 30\% e famílias com três pessoas, 19,8\%. A figura 7 apresenta o número de habitantes por residência, mostrando que há uma maior tendência em relação aos dados do IBGE (2007), pois conforme esses dados, a média total da população urbana do município de Passo Fundo é 3,37 habitantes por domicílio, somando-se a um total de 162.428 habitantes que ocupam 48.228 domicílios.

Foi investigada a cidade de origem dos moradores, pois Passo Fundo por sua importância regional atrai muitas pessoas. Em muito desses casos, as pessoas acabam por ocupar periferias ou áreas irregulares, por não possuírem condições de instalar-se em locais apropriados. 


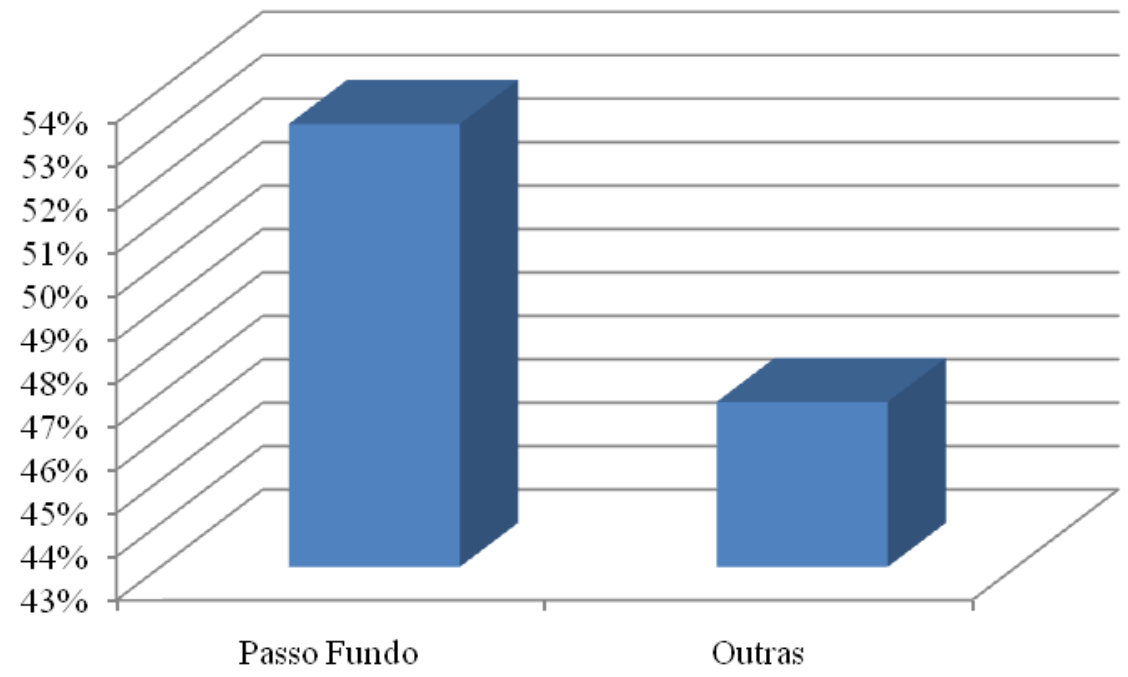

Figura 8 - Origem dos moradores da área pesquisada

Os resultados mostraram que a grande maioria é proveniente da própria cidade, $53,21 \%$, sendo os outros 46,79\% de diversas cidades, como por exemplo, Erechim (5,5\%), Carazinho e Marau (4,59\%).

Quanta à renda familiar dos moradores, na busca de compreender os motivos que os levaram a optar morar em um local como o estudado, constatou-se conforme exposto na figura 9 os ganhos recebidos mensalmente pelas famílias ribeirinhas em salários mínimos (S.M.).

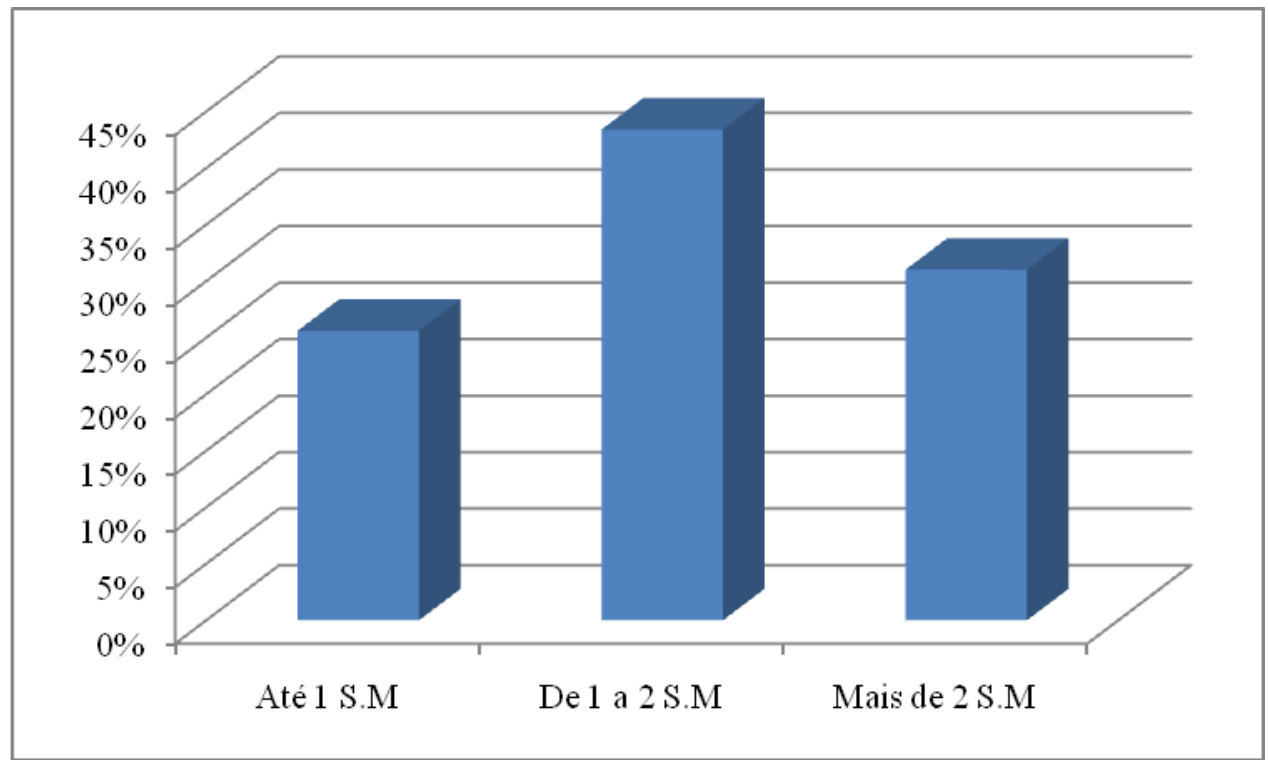

Figura 9 - Renda mensal média dos moradores da região ribeirinha. 
Do total de moradores 25,6\% recebem até um salário mínimo, 43,4\% recebe de um a dois salários mínimos e $31 \%$ recebem mais de dois salários mínimos, comprovando que a população ribeirinha é essencialmente de famílias de baixa renda.

Analisou-se o percentual de pessoas que trabalham com carteira assinada e na informalidade. A maioria apresenta trabalho formal com 45,11\%, contra 39,85\% na informalidade. Os dados completos estão na figura 10:

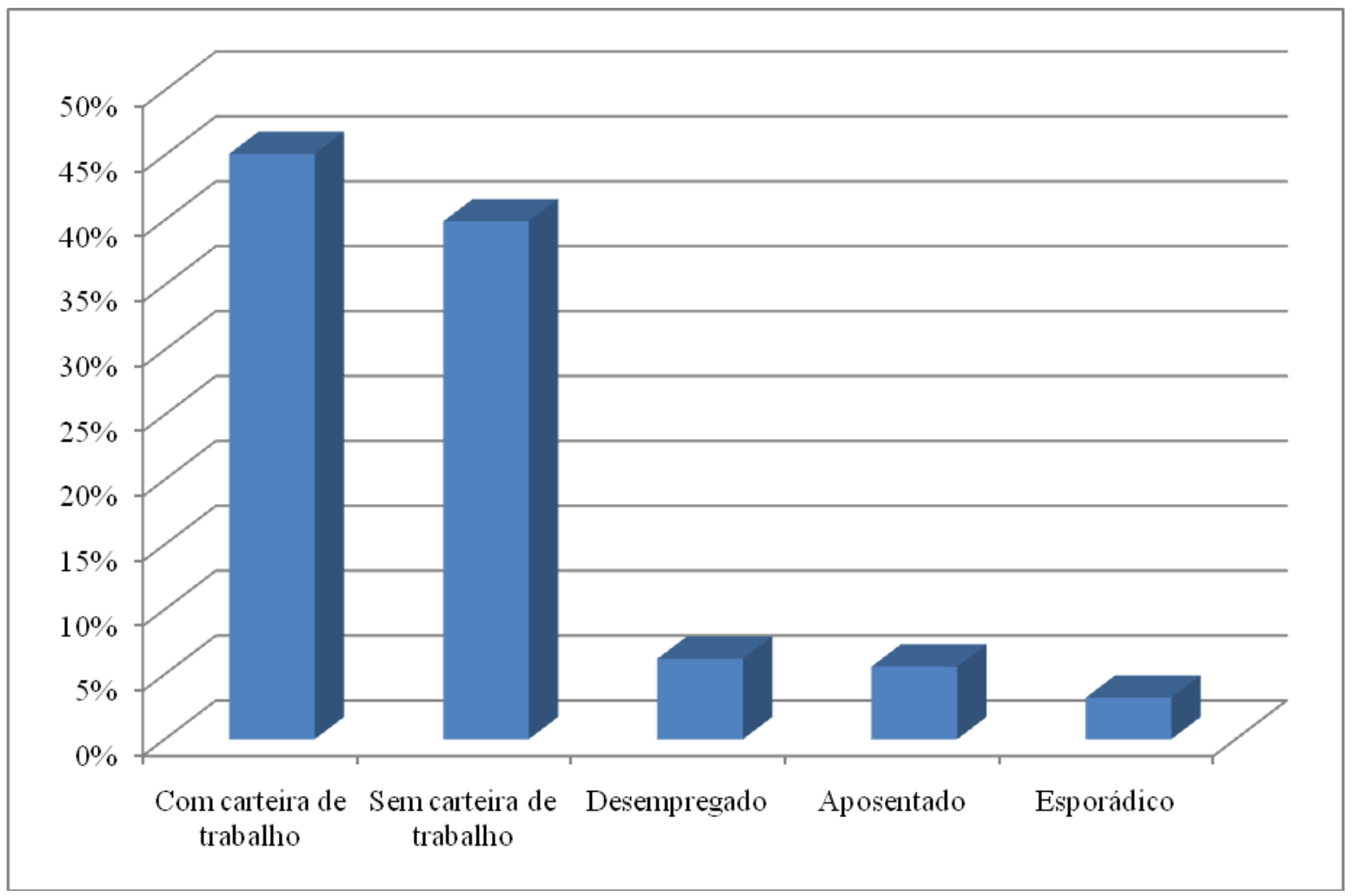

Figura 10 - Forma de emprego.

Seguindo tal raciocínio, foi questionado se as famílias recebem algum tipo de ajuda governamental. Aferiu-se que $80 \%$ dos moradores indicaram que não são atendidos por algum programa governamental de complementação de renda.

Esses números podem ser explicados devido à renda das famílias, uma vez que os programas governamentais têm como objetivo atender famílias que possuem renda per capita menor que $\mathrm{R} \$ 100,00$ mensais.

Quanto às deficiências de infraestrutura, o problema mais comum em locais como esses, onde não há planejamento, são inundações. Segundo os moradores, a maioria das famílias, já teve suas casas inundadas. Uma pequena parcela ainda não 
foi prejudicada por esse problema. A representação deste fato é observada na figura 11 .

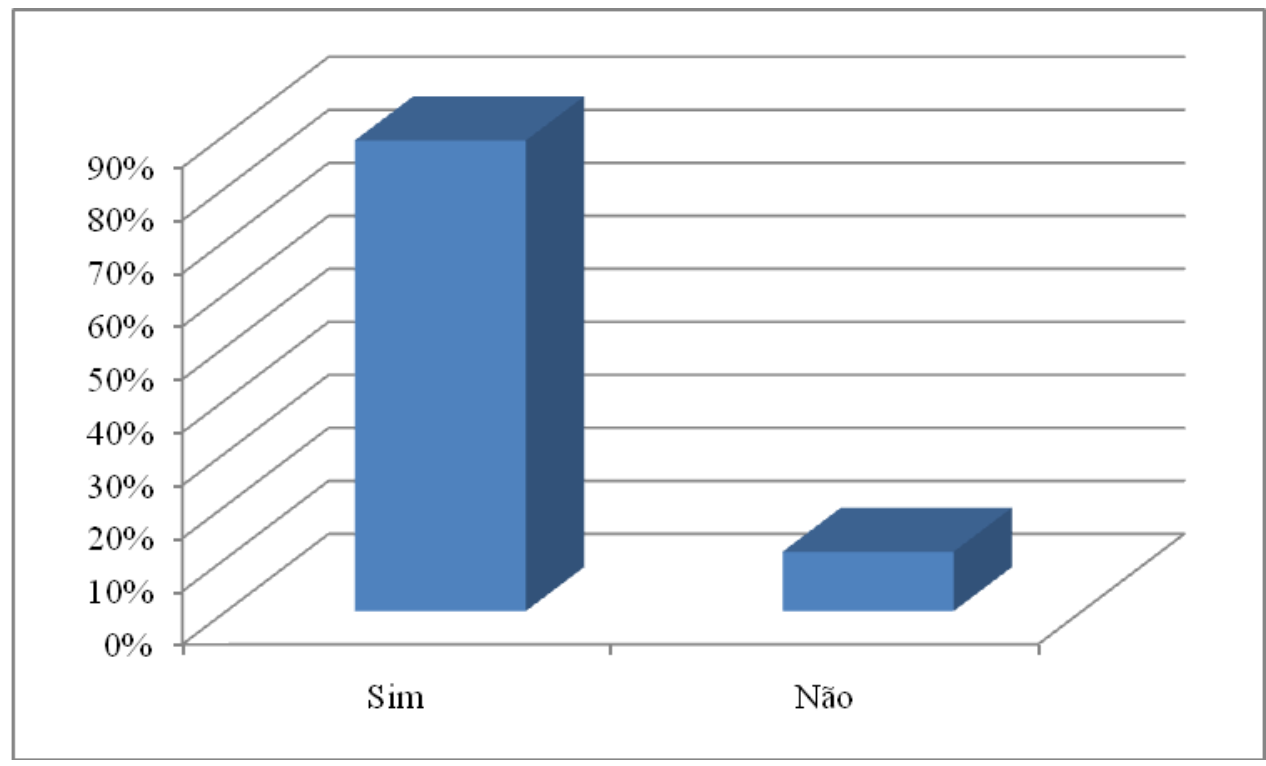

Figura 11 - Ocorrência de frequentes inundações no local.

Frente às perguntas anteriores, questionou-se a cerca dos maiores problemas de infraestrutura e políticas públicas a serem solucionados. Os dados da figura 12 apresentam a resposta dos moradores.

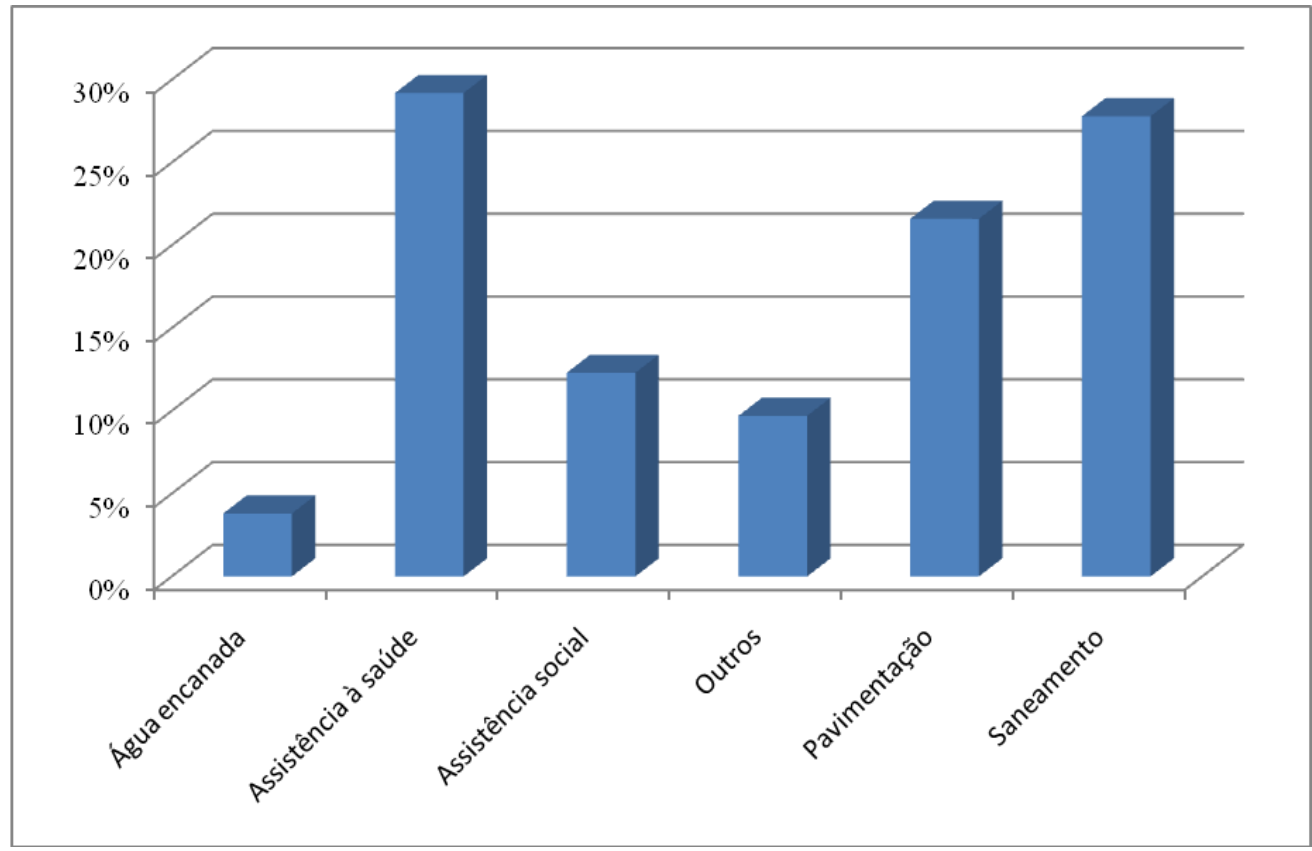

Figura 12 - Problemas de infraestrutura mais urgentes para serem solucionados. 
As maiores deficiências apontadas foram assistência à saúde, com 29,2\%, seguida de saneamento com $27,8 \%$. Isso vem demonstrar que a população sabe que esses dois itens são fundamentais para iniciar-se uma melhoria de qualidade de vida, em termos de saúde e melhorias ambientais.

Questionados sobre qual o destino final do esgoto produzido em suas residências, conforme a figura 13 , apenas $10,3 \%$ apontaram a existência de fossa séptica.

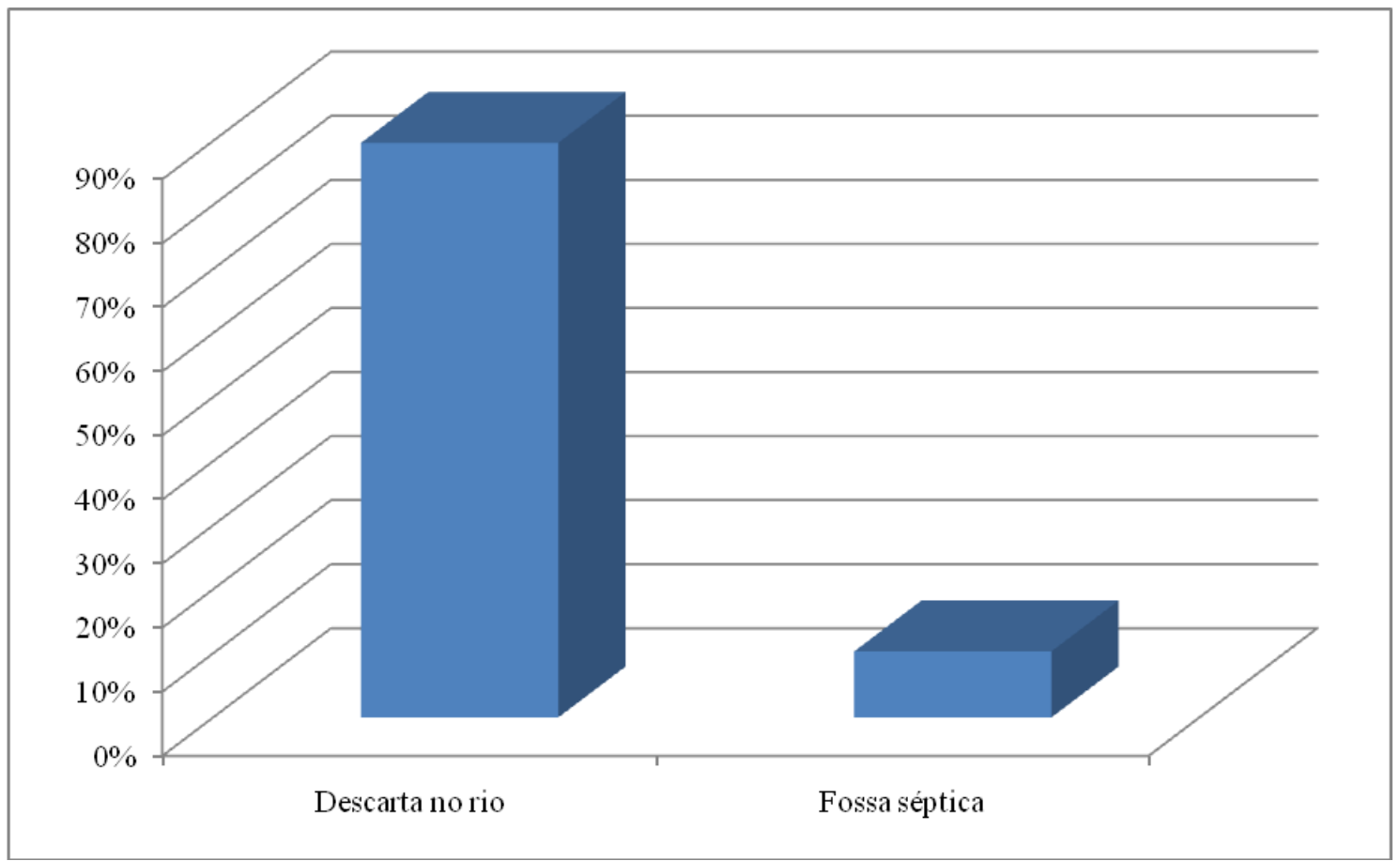

Figura 13 - Destino final do esgoto produzido nas residências.

Tal situação demonstra que não só a população tem motivos para eleger o saneamento como prioridade, mas também as autoridades locais, pois a situação é preocupante: $89,7 \%$ lançam, sem qualquer tratamento, seus esgotos nos rios.

$\mathrm{Na}$ abordagem da qualidade de vida da população ribeirinha, foi questionado se recebem frequentemente a visita de Agentes de Saúde. Os números referentes a esse programa governamental estão apresentados na figura 14. 


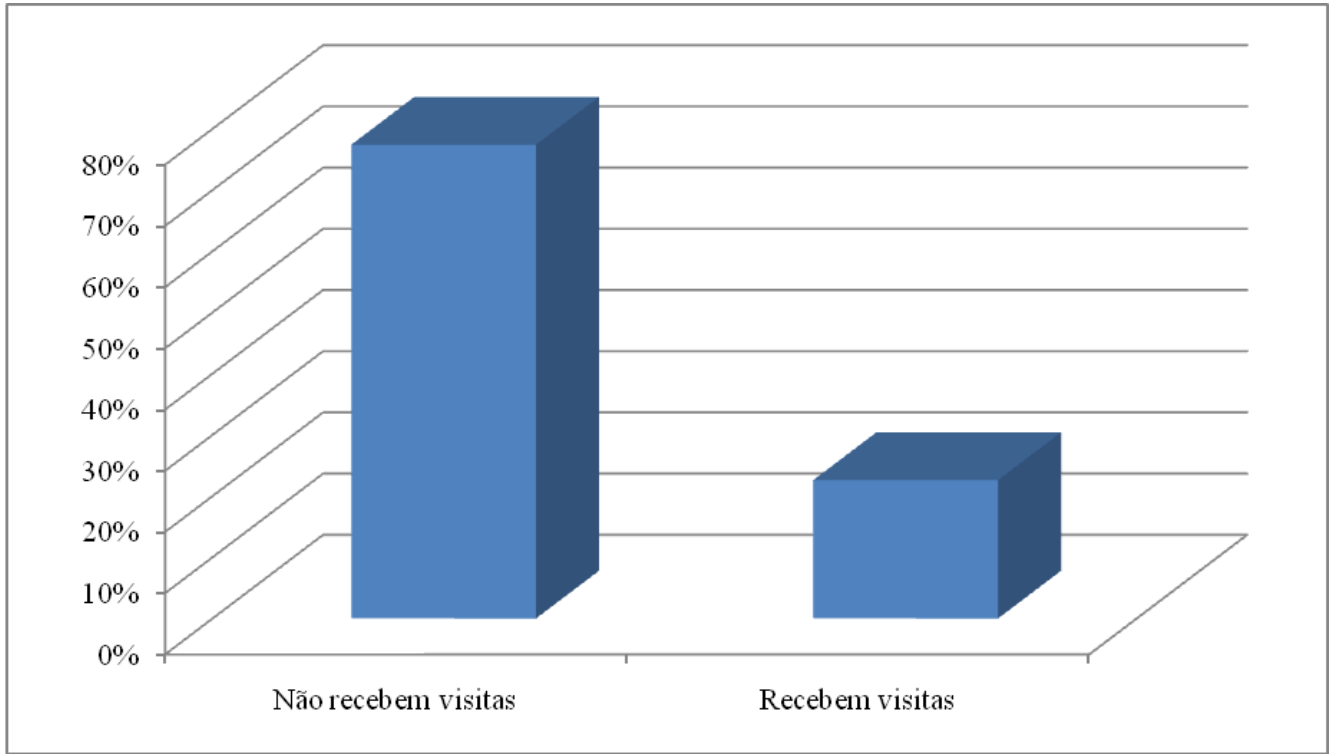

Figura 14 - Destino final do esgoto produzido nas residências.

Dos entrevistados, 77,4\% dizem não receber visita dos profissionais, enquanto $22,6 \%$ recebem com regularidade a visita desses profissionais.

Questionou-se sobre as doenças que podem ser transmitidas pela água e se já haviam contraído. A maioria dos moradores, 54,9\% diz não ter sido contaminado por doenças transmitidas pela água, sendo, entre os que já foram contaminados, a doença mais citada diarréia. Os números estão apresentados na figura 15.

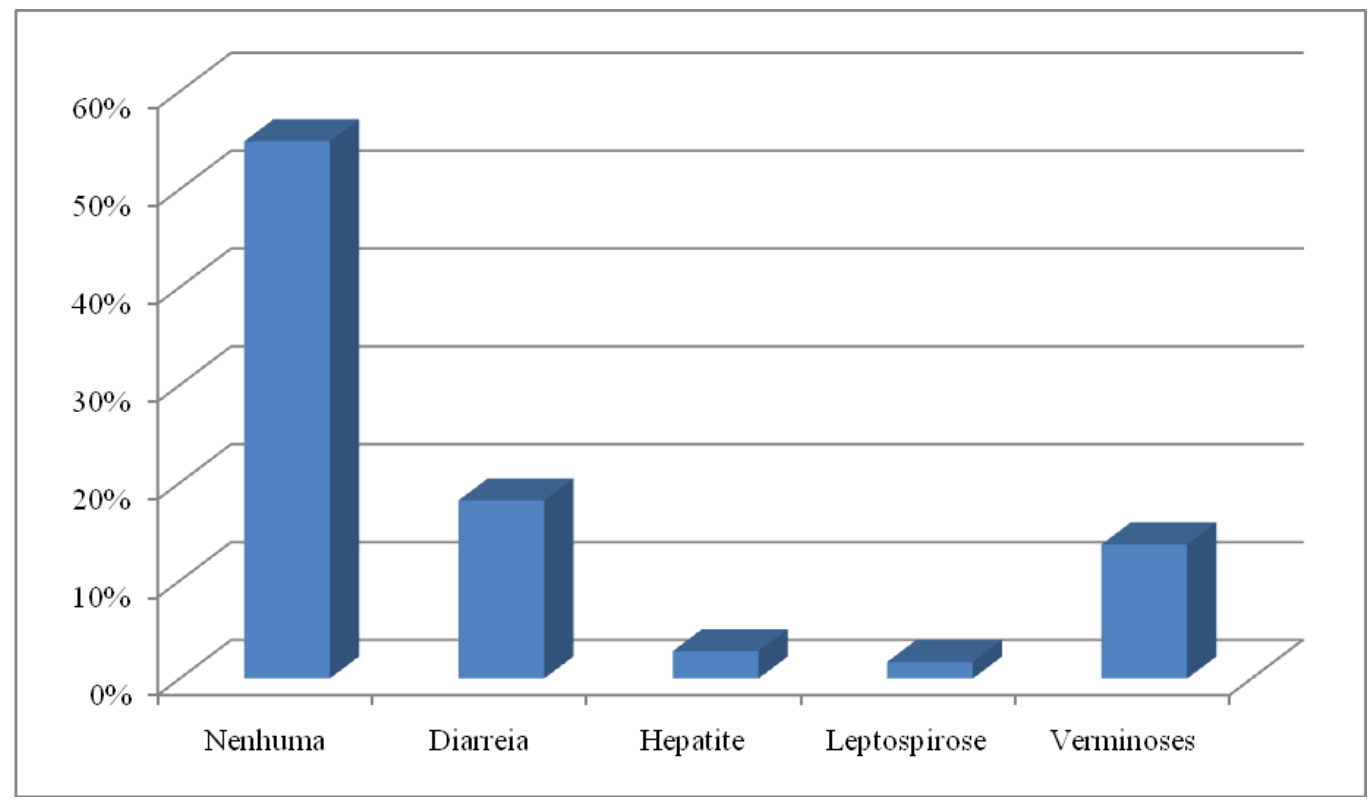

Figura 15 - Enfermidades mais frequentes dentro do grupo familiar. 


\section{Análise microbiológica da água}

A análise microbiológica da água foi realizada com o objetivo de se identificar a presença de coliformes na água da nascente e no perímetro urbano. Esses resultados estão apresentados na tabela 1, e divididos por suas respectivas classes, conforme orienta a Resolução do CONAMA 357/05. Nesse contexto, a análise realizada na nascente do arroio Santo Antônio comprovou que a água encontra-se imprópria para o consumo humano, pois apresentou 200 coliformes termo-tolerantes por $100 \mathrm{ml}$ de água, e para o consumo humano esta mesma resolução exige, na Classe 1, menos de 200 coliformes termo-tolerantes por $100 \mathrm{ml}$ de água. Mas pela Classe 2, o arroio está permitido para banho, atividades de lazer e pesca, pois ficou abaixo do máximo tolerado.

A análise da água realizada dentro do perímetro urbano apresentou dados preocupantes, no que se refere à qualidade microbiológica da água do arroio. Nesse sentido, através da análise comprovou-se que a água do arroio está totalmente contaminada, com 54.000 coliformes termo-tolerantes por $100 \mathrm{ml}$ de água, fato que conforme o CONAMA 357/2002 torna o arroio Santo Antônio impróprio para qualquer atividade humana.

Tabela 1- Comparativo entre a água da nascente e a da zona urbana do arrio Santo Antônio.

\begin{tabular}{|c|c|c|c|c|c|}
\hline \multirow{3}{*}{ Local } & \multirow{3}{*}{$\begin{array}{c}\text { Quantidade } \\
\text { (NMP/100ml) }\end{array}$} & \multicolumn{4}{|c|}{ Padrão } \\
\hline & & \multirow{2}{*}{$\begin{array}{c}\text { Portaria } 05 / 04 \\
\text { MS }\end{array}$} & \multicolumn{3}{|c|}{ Resolução CONAMA 357/05 } \\
\hline & & & Classe 1 & Classe 2 & Classe 3 \\
\hline Nascente & 200 & \multirow{3}{*}{ Ausente } & \multirow{3}{*}{200} & \multirow{3}{*}{1000} & \multirow{3}{*}{2500} \\
\hline Zona & & & & & \\
\hline Urbana & 54000 & & & & \\
\hline
\end{tabular}

Fonte: Análise realizada pelo CEPA-UPF a pedidos dos autores. 


\section{Considerações finais}

O caminho percorrido pelo arroio Santo Antônio tornou-se muito meândrico, em virtude de suas margens estarem sendo assoreadas constantemente. O mau uso do solo, aliado a um processo de desmatamento progressivo da mata ciliar no perímetro urbano e à concentração industrial, têm proporcionado um assoreamento cada vez mais acelerado, de grande parte de seus leitos fluviais, colocando em risco toda a malha hidrográfica.

A grande maioria da população ribeirinha vem sendo vítima de inundações constantes do arroio Santo Antônio devido às degradações que o mesmo vem sofrendo ao longo dos anos e pelo fato de as pessoas residem numa planície de inundação em épocas que o arroio transborda.

Os problemas de infraestrutura também ficam evidenciados, e ao mesmo tempo em que a população espera que estes sejam resolvidos para que a qualidade de vida daquele local seja elevada, aliada a qualidade ambienta.

Por fim, esse trabalho teve a intenção de servir de aporte teórico a futuros trabalhos científicos, visando o estudo de qualidade hídrica e as relações dos habitantes ribeirinhos com o estudo. O estudo socioambiental do arroio Santo Antônio, revela um processo de violenta degradação, que se manifesta através das alterações na vegetação e no lançamento de esgotos domésticos e de resíduos sólidos.

\section{Referências bibliográficas}

BRAGA, R.; CARVALHO, P. F. Recursos Hídricos e Planejamento Urbano e Regional. 1. ed. Rio Claro: Laboratório de Planejamento Municipal, 2003 (Boletim Técnico, 131).

CHAFFUN, N. Dinâmica global e desafio urbano. In: Bonduki, N. (Org.) Habitat: as práticas bem-sucedidas em habitação, meio ambiente e gestão urbana nas cidades brasileiras. 2. ed. São Paulo: Studio Nobel, 1997.

BRASIL. Conselho Nacional do Meio Ambiente - CONAMA. Resolução no 303. Publica no D.O.U. de 13 de março de 2002. Disponível em:〈www.mma.gov.br> . Acessado em 10 de janeiro de 2010. 
Conselho Nacional do Meio Ambiente - CONAMA. Resolução $\mathrm{n}^{\circ} 357$. Publica no D.O.U. de 18 de maio de 200. Disponível em:〈www.mma.gov.br> . Acessado em 10 de janeiro de 2010.

DAMAS, T. Expansão urbana e a problemática ambiental - estudo de caso do Lago Jaboti, Apucarana (PR). Revista Caminhos de Geografia, Uberlândia, v. 15, n. 6, p. 93-107, Jun. 2005.

DUARTE, W. de. O; BRITO, J.L. S.; Mapeamento do uso da terra e cobertura vegetal da Bacia do rio Uberabinha utilizando imagens dos Satélites Landsat 7 E CBERS 2. Revista Horizonte Científico, v. 1, n. 6, p. 1-20, 2006.

ELDHO, T, I. Sustainable Water Management and Pollution Abatement through Common Effluent Treatment Plants in Industrial Areas. Workshop 1: International Targets and National Implementation. World Water Week in Stockholm, Stockholm, pp. 12-18, 2007.

FANTON, G. Diagnóstico das condições ambientais do espaço urbano do Município de David Canabarro-RS. . Monografia do Curso de Geografia, do Instituto de Ciências Exatas e Geociências, da Universidade de Passo Fundo. Passo Fundo, 2007.

GOOGLE MAPS. Imagem. Disponível em: <http://www.google.com.br>. Acesso em: 18 ago. 2007.

IBGE, Censo 2007. Dados disponíveis em: http:<//www.ibge.gov.br/cidadesat $>$ Acesso em: 30 mar. 2008.

LEFF, E. A complexidade ambiental. São Paulo: Cortez, 2003.

LORENSINI, C.: TRINDADE, C.; PIPPI, L.G. A.; CARTANA, M. Equívocos no planejamento urbano de Santa Maria - RS. 2008. Disponível em: <http://www.vitruvius.com.br>. Acesso em: 31/5/2008.

MAgOSSI, L. R.; BONACELlA, P. H. Poluição das Águas. 1. ed. São Paulo: Moderna, 2003.

MARQUES NETO, R.; VIADANA, A. G. Abordagem biogeográfica sobre a fauna silvestre em áreas antropizadas: o sistema Atibaia-Jaguari em Americana (SP). Revista Sociedade \& Natureza, Uberlândia, v. 18, n.5, p. 5-21, 2006. 
NECKEL, A. Recuperação Socioambiental de área verde urbana degradada Loteamento Cidade Universitária - Passo Fundo - RS. 2007. Monografia (Curso de Geografia) - Instituto de Ciências Exatas e Geociências, Universidade de Passo Fundo, Passo Fundo, 2007.

NEFUSSI, N.; LICCO, E. Solo Urbano e Meio Ambiente. UEM - Universidade Estadual de Maringá, 2005. Disponível em: < http://www.nemo.uem.br/>, acesso em: 13de maio de 2008.

OliveirA, F. X. de. Annaes do Município de Passo Fundo. [Coord. por Marília Mattos e outros]. Passo Fundo: Universidade de Passo Fundo, 1990.

PLANO DIRETOR DE DESENVOLVIMENTO INTEGRADO - PDDI. Prefeitura Municipal de Passo Fundo - RS. Disponível em: http://www.pmpf.gov.br. Acesso em: 13 de gosto de 2007.

SOUZA, M. L. de. Mudar a cidade: uma introdução crítica ao planejamento e à gestão urbanos. 3. ed. Rio de Janeiro: Bertrand Brasil, 2004.

TAVARES, A. B.; da Cruz, S. P.; de LOLLO, J. A. Geoindicadores para a caracterização de estado de diferentes ambientes. Estudos Geográficos: Revista Eletrônica de Geografia, Rio Claro, v.5, n.2, p.51-68, Nov. 2007.

TEIGA, P.; PEDROSO, L.; da SILVA, L. M. VELOSO-GOMES, F. O envolvimento da população na reabilitação de um rio urbano (Barcarena - Oeiras). In: Congreso Internacional de Educación Ambiental dos Países Lusófonos e Galiza, 1, Santiago de Compostela. Anais... España: CEIDA, p. 1-16, 2007.

Recebido para publicação em janeiro de 2010 Aprovado para publicação em agosto de 2010 